\title{
Análise das monitorias de Cálculo e de Física: um estudo de caso em cursos de Engenharia ${ }^{+*}$
}

Jeronimo Becker Flores ${ }^{1}$

Valderez Marina do Rosário Lima²

Caren Rejane de Freitas Fontella ${ }^{3}$

PUC - RS

Porto Alegre - RS

\section{Resumo}

Neste artigo analisamos as monitorias de Cálculo e de Física desenvolvidas por uma Instituição de Ensino Superior (IES). A pesquisa tem uma abordagem qualitativa do tipo estudo de caso. Partimos da leitura analítica de uma base teórica pertinente ao tema e, na sequência, realizamos entrevistas com os professores responsáveis pelas monitorias. O material foi analisado à luz da Análise Textual Discursiva (ATD). Como principais resultados indicamos que, apesar dos pontos comuns, não existe um trabalho integrado entre as disciplinas de Cálculo e de Física. Além disso, apontamos a necessidade de um trabalho pedagógico conciliado entre professores, bolsistas e estudantes. Também consideramos a necessidade de estudos futuros que reforcem e ampliem as discussões aqui desenvolvidas.

Palavras-chave: Monitoria. Cálculo; Monitoria de Física; Ensino Superior.

\footnotetext{
${ }^{+}$Analysis of tutoring in Calculus and Physics: a case study in engineering courses

* Recebido: novembro de 2016.

Aceito: fevereiro de 2017.

${ }^{1}$ E-mail: jeronimobecker@gmail.com

2 E-mail: valderez.lima@pucrs.br

3 E-mail: caren.fontella@gmail.com
} 


\begin{abstract}
In this article, we analyzed the Calculus and Physics' tutoring developed by a Higher Education Institution (HEI). The research consists of a qualitative approach of a type of case study. We began from the analytical reading of a theoretical basis which was relevant to the theme and then, we performed interviews with the professors responsible for the monitoring. The material was analyzed in the light of the Discursive Textual Analysis (DTA). As main results, we indicated that, in spite of the commonalities, there is no integrated work between Calculus and Physics subjects. In addition, we aimed the need of a reconciled pedagogical role among teachers, scholarship students and common ones. We also considered the need of future studies that reinforce and increase the discussions developed here.
\end{abstract}

Keywords: Tutoring; Calculus; Physics' tutoring; Higher Education.

\title{
I. Introdução
}

O ensino e a aprendizagem de Cálculo e de Física são discutidos em diversas pesquisas produzidas na academia em várias universidades do país, por distintos teóricos. Até a década de 1970, conforme afirma Nitsch, Bazzo e Tozzi (2004), o quadro de professores das escolas de Engenharia compreendia profissionais especialistas em suas áreas e que possuíam uma visão tradicional de ensino. Esses profissionais pouco conheciam sobre metodologias de ensino e didática, e simplesmente transmitiam seu conhecimento aos estudantes de acordo com suas experiências profissionais. Entretanto, esse panorama muda com o tempo à medida que profissionais da Educação passam a implementar ações pedagógicas no ambiente de ensino.

Encontramos poucas produções acerca das monitorias, de forma que pouco se sabe sobre seu papel, tanto no que diz respeito à aprendizagem dos estudantes, à formação do próprio monitor ou, ainda, a como elas se estruturam, apesar da monitoria estar presente, de forma expressiva, em escolas de Engenharia do país. Sobre este tema, destacamos os trabalhos realizados por Rezende (2003), Oliveira e Raad (2012), Moreira (2014) e Da Silveira (2013).

Com a presente pesquisa ${ }^{4}$, cujo objetivo é compreender como as monitorias de Cálculo e de Física estão sendo organizadas e desenvolvidas, procuramos contribuir com as discussões que já vêm sendo realizadas nesta área, ampliando e aprofundando tópicos referentes à qualificação dos processos de ensino e aprendizagem em um estudo que mantém sua atenção nas monitorias de Cálculo e de Física em cursos de Engenharia e na forma como elas estão sendo

\footnotetext{
${ }^{4} \mathrm{O}$ princípio desta pesquisa foram as discussões desenvolvidas no grupo de pesquisa denominado "Ensino, aprendizagem e formação de professores de ciências: desafio para o século XXI, vinculado à Pontifícia Universidade Católica do Rio Grande do Sul (PUCRS).
} 
estruturadas dentro das IES. Justificamos este trabalho a partir de sua relevância para a área da Educação, uma vez que a leitura do referencial teórico nos indicou a existência de poucas produções sobre o tema abordado. Nossas experiências como estudantes, monitores e professores de Cálculo e de Física também se constituíram elementos expressivos para a escolha do objeto de estudo.

Desta forma, neste artigo apresentamos um estudo de caso sobre a forma como são estruturadas e ofertadas as monitorias de Cálculo e de Física em uma Instituição de Ensino Superior situada no Estado do Rio Grande do Sul. Para isso realizamos duas entrevistas semiestruturadas, uma com o professor-monitor de Cálculo e uma com o professor-monitor de Física.

O artigo encontra-se organizado em cinco seções, além da introdução, na qual justificamos o estudo e apresentamos seu objetivo. A seguir, na seção O ensino de Cálculo e de Física, trazemos um panorama das disciplinas de Cálculo e de Física e algumas considerações sobre as dificuldades que lhes são próprias. Na seção Monitoria de Cálculo e de Física apresentamos um breve histórico das concepções acerca da constituição das monitorias de Cálculo e de Física, no qual situamos os propósitos da monitoria como uma ação que visa qualificar o processo de aprendizagem. A seção Metodologia é a parte do texto em que apontamos a abordagem metodológica utilizada na pesquisa e as estratégias para construção e análise do corpus da pesquisa. A seção Resultados e discussões refere-se à análise e às reflexões acerca dos dados coletados. Por fim, na seção Considerações para futuros estudos, tratamos das considerações para futuras interlocuções.

\section{O ensino de Cálculo e de Física}

As dificuldades que permeiam o ensino de Cálculo e de Física têm se constituído em pauta comum tanto em pesquisas acadêmicas quanto nas falas que frequentemente ouvimos nos corredores das IES. Autores como Cavasotto e Viali (2011), Gerab e Valério (2014), dentre outros, trazem indicativos de que o ensino dessas disciplinas, no Ensino Superior, tem se constituído um desafio para os estudantes.

Os cenários percebidos nas disciplinas de Cálculo e de Física parecem ser semelhantes. A teoria sinaliza insucessos, reprovação e evasão (GERAB; VALÉRIO, 2014). Diversos pesquisadores têm procurado elucidar os elementos que constituem esse panorama, e tentaremos expor seus principais argumentos para essa situação nos próximos parágrafos.

Inicialmente consideramos os pontos de vista de Cury e Cassol (2004, p. 29), que apontam a existência de "dificuldades de abstração e generalização, o que leva muitos alunos a reprovar na disciplina ou evadir-se dos cursos que possuem estas disciplinas em seus currículos". A essas constatações somam-se lacunas em fundamentos como Álgebra e Geometria, oriundas da Educação Básica, as quais desencadeiam um quadro de dificuldades para os estudantes e para os professores. As autoras consideram necessário identificar os erros dos estudantes para 
que, desse modo, seja possível o desenvolvimento de ações que visem superá-los, ou seja, formar a base teórica que o estudante, por algum motivo, não conseguiu constituir ao longo de sua formação básica. Na visão delas, o erro deixa de ser negativo e passa a ser visto com o ponto de partida para a ação docente. Essa perspectiva pode levar ao preenchimento das ausências que, eventualmente, o estudante traga em seus conhecimentos.

É possível que, em determinados casos, exista um hiato, entre os conteúdos do Ensino Médio e Superior, passível de gerar insucessos e tensionamentos entre as partes. Esse assunto é amplamente discutido por Cavasotto e Viali (2011), que analisam os erros cometidos nas aulas de Cálculo e constatam obstáculos e erros intrínsecos às equações do primeiro grau, radiciação e manipulação algébrica, por exemplo. Em Física encontramos um panorama similar. Gerab e Valério (2014, p. 2) argumentam que os ingressantes nas primeiras disciplinas de Física "às vezes se defrontam com dificuldades decorrentes das lacunas do seu conhecimento em Matemática e em Física deixadas por um ensino médio deficitário". Esses obstáculos já aparecem no início do curso, no mesmo momento em que o estudante precisa se adaptar ao contexto do Ensino Superior.

Oliveira e Raad (2012) aprofundam a discussão, propondo que as adversidades, sobretudo em Cálculo, não estão apenas relacionadas aos conteúdos, mas à existência de uma cultura. Evidenciam que a reprovação é uma tradição, sendo vista por estudantes e professores como algo comum e até "normal". Ponderam que ainda hoje há quem relacione a qualidade de um curso ao seu índice de reprovação. Um professor ou uma disciplina podem ser considerados melhores na medida em que seus alunos reprovam mais. Os autores criticam essa visão, defendendo que é necessário redimensionar as concepções que permeiam o ensino nesse caso. Para eles, o insucesso não representa qualidade, e a qualificação dos processos de ensino e de aprendizagem de Cálculo não pode ser uma iniciativa que aponte apenas o conteúdo, sendo necessárias uma reflexão maior sobre o que gera esses obstáculos e uma revisão de ações e concepções.

Soares e Sauer (2004) reforçam essa ideia, considerando necessário adequar o ensino de ciências exatas para Engenharia às demandas contemporâneas. Isso implica superar a transmissão de informações e direcionar o ensino para a criação de estratégias em que preponderem o diálogo e a reflexão. Inserem-se nesse aspecto o incentivo à pesquisa e o desenvolvimento de habilidades como testar, ler, interpretar e conjecturar, em movimentos interativos entre estudantes e professores (SOARES; SAUER, 2004).

Assim, consideramos que o ensino de Cálculo e de Física insere-se em um contexto de complexidade, de críticas e, por que não dizer, de fracassos. A literatura disponível mostra que existem algumas iniciativas para alterar esse quadro, dentre as quais se destaca a monitoria, nosso próximo assunto.

\section{Monitoria de Cálculo e de Física}

A problemática que envolve o ensino e a aprendizagem de ciências exatas aparentemente também está sendo percebida pelas IES, que vêm desenvolvendo ações para qualificar 
esses processos. Como já mencionado anteriormente, o foco desta investigação são as monitorias de Cálculo e de Física ofertadas pelas IES como mecanismo de ensino e aprendizagem. Na sequência, abordamos os aspectos teóricos dessas monitorias.

Moraes e Torres (2003, p. 1) esclarecem que o vocábulo monitoria origina-se do sistema educacional clássico e remete ao estudante que, por ter avançado algumas etapas, auxiliava o professor nas suas tarefas. Monroe (1974) complementa lembrando que, na Grécia Antiga, a monitoria era realizada por um pedagogo que colaborava com as atividades do mestre.

No Brasil, a monitoria em universidades iniciou na década de 1960 e, conforme expressa Dias (2007, p. 37), "o programa de Monitoria nas universidades brasileiras foi iniciado com a Lei 5540, de 28 de novembro de 1968, que fixou normas de organização e funcionamento para o Ensino Superior". Nesse período o monitor era um estudante com bom desempenho acadêmico, demonstrando conhecimentos técnicos acerca da disciplina de atuação. Ele era orientado pelo professor responsável pela disciplina e tinha a tarefa de prestar auxílio aos colegas e ao professor nas aulas, nas pesquisas e em outras atividades. Vale a pena destacar que o monitor passava por um processo seletivo, não podendo ter sido anteriormente reprovado na disciplina em que iria atuar (DIAS, 2007).

Atualmente as IES organizam as monitorias segundo legislação interna específica. Dias (2007) informa que, especialmente a partir da década de 1980, a monitoria sofreu um processo de descaracterização. A pesquisa ganhou maior relevância em detrimento do ensino, e a permanência dos monitores estava mais condicionada à potencialização do currículo do que à participação efetiva nos programas. Desse modo, parece ter havido uma perda nos aspectos pedagógicos e no próprio interesse do monitor em exercer funções relativas ao ensino.

Quando falamos em ciências exatas, a monitoria parece ser uma possibilidade interessante para que os estudantes qualifiquem seu processo de aprendizagem, em razão do número de reprovações em casos que não há ocorrência de monitoria. Ajambuza, Silveira e Gonçalves (2004) e Gerab e Valério (2014) destacam que é necessário ações visando à aprendizagem do estudante e proporcionadas em momentos além da sala de aula. No entanto, esse entendimento não é unânime, conforme argumentaremos nos próximos parágrafos.

Cavasotto e Viali (2011) questionam a forma como as monitorias são organizadas atualmente. Eles indicam que elas são pouco procuradas pelos estudantes e que são organizadas sob uma perspectiva de transmissão de informações. A procura maior pela monitoria por parte dos discentes concentra-se nas vésperas de avaliações, o que tende a não contribuir efetivamente com a aprendizagem dos estudantes, produzindo um efeito momentâneo e focado apenas na nota. Os autores sugerem uma revisão desse modelo, com a adoção de "metodologias que possibilitem uma participação diferente por parte do educando, que ele passe de uma atitude passiva para uma postura ativa na construção do conhecimento" (CAVASOTTO; VIALI, 2011, p. 31). Pensar segundo essa linha nos leva a reconsiderar as concepções que possam permear as monitorias. Parece não ser suficiente apenas olhar para os conteúdos, sendo necessário rever as formas de ensino. 
Argumentos semelhantes são trazidos por Oliveira e Raad (2012). Eles problematizam a cultura intrínseca ao Cálculo, na qual a reprovação é considerada um elemento próprio e genuíno da disciplina. Ações pedagógicas não são suficientes para romper com esse modelo, uma vez que tendem a visar apenas o conteúdo, o que acaba por reforçar a cultura de insucesso já existente. Para os autores as monitorias se constituem em ações inócuas, paliativos que não formam uma base de pensamento matemático nem completam as ausências conceituais. Em relação à Física, disciplina que também faz parte do estudo, o cenário parece não ser diferente do apresentado pelos autores.

Como contraponto, Dias (2007) expõe aspectos positivos em relação à monitoria. Segundo a autora, os benefícios não se limitam ao estudante que frequenta a monitoria, mas abarcam toda a estrutura. O bolsista de monitoria, no mesmo compasso que presta auxílio ao seu colega, também pode aprender a partir do envolvimento em atividades pedagógicas e da relação social estabelecida com os seus pares. Assim, faz-se necessário uma estrutura de apoio ao bolsista para que ele não fique isolado nas suas tarefas e não seja apenas um aluno que auxilie a resolver contas.

Parece ser fato que um acadêmico não tenha condições plenas de desencadear os processos de ensino e aprendizagem, sendo necessária a supervisão e a orientação de uma equipe pedagógica de apoio. Percebemos a preocupação da autora nesse sentido quando ela destaca que:

Nesse contexto, não cabe expor o estudante-monitor a situações estranhas a esse processo de formação como, por exemplo, substituir o professor, avaliar os colegas estudantes, desenvolver pesquisas ou coleta de dados que não tenham relação de pertinência com a atividade docente, proposta no projeto interdisciplinar, realizar atividades meramente mecânicas, administrativas ou que não tenham articulação com a atividade docente (DIAS, 2007, p. 41).

Consideramos que para o sucesso da monitoria o estudante bolsista não deve ficar isolado em sua tarefa. A busca pela dimensão coletiva entre bolsista-monitor, professor-monitor, professor da disciplina e outros que estejam envoltos no processo parece ser o mais indicado para que essas ações possam contribuir efetivamente para a formação acadêmica, pessoal e profissional.

A própria relação que os estudantes estabelecem entre si pode ser vista como um ponto favorável da monitoria. Um setor em que os estudantes possam estudar aprender e socializar também pode se constituir em uma possibilidade de fomento à autonomia, fato amplamente preconizado por Freire (1996), que define como condição essencial para o ensino a aceitação da autonomia e da identidade do estudante. Esses argumentos pressupõem a constituição de contextos que propiciem ao estudante o desenvolvimento da autonomia. A monitoria pode ganhar esse contorno, instituindo-se como um espaço para a construção do conhecimento.

Esse espaço também pode ser utilizado para o ensaio de experiências inovadoras. Dias (2007) exemplifica ações que utilizam tecnologias digitais como suporte para a aprendizagem. 
Müller (2015) recomenda o uso de objetos de aprendizagens digitais como uma possibilidade de preencher as lacunas conceituais dos estudantes e também de estabelecer uma relação entre o estudante e o objeto do conhecimento. Ela enfatiza a importância do trabalho articulado entre o professor da disciplina e o sistema de monitoria. Para a autora o professor precisa identificar a lacuna na aprendizagem do estudante a fim de que a monitoria possa efetivar um trabalho direcionado para tal. Esse argumento é corroborado por Cury e Cassol (2004), as quais consideram que geralmente o estudante não consegue avançar pois não é capaz de identificar suas dificuldades. Parece ser consenso que a monitoria não pode ser uma atividade isolada, sendo necessário um trabalho articulado entre as distintas partes.

A seguir, trataremos dos aspectos metodológicos que nortearam esta pesquisa, trazendo a abordagem utilizada, o tipo de pesquisa e o método utilizado para análise do corpus.

\section{Metodologia}

Este estudo constitui-se como uma pesquisa de abordagem qualitativa, do tipo estudo de caso, cujos procedimentos de análise seguiram a Análise Textual Discursiva, em acordo com os pressupostos teóricos de Moraes e Galiazzi (2007).

No entendimento de Richardson (1999), o emprego da abordagem qualitativa possibilita a descrição de um fenômeno na totalidade de sua complexidade, almejando compreensões amplas que abarcam tanto o sujeito quanto o contexto que o circunda. Dentro desse enfoque, assumimos como tipo de pesquisa o estudo de caso, que tem se tornado uma estratégia muito utilizada quando o objetivo dos pesquisadores é responder "como" e "por que" certos fenômenos ocorrem e quando há pouca possibilidade de controle sobre os eventos estudados, os quais só poderão ser analisados dentro de algum contexto de vida real (YIN, 2010).

Norteados pelo problema de pesquisa descrito - como as monitorias de Cálculo e de Física para os cursos de Engenharia são organizadas e desenvolvidas em uma Instituição de Ensino Superior (IES) -, estruturamos o estudo de caso com o objetivo de compreender como as monitorias de Cálculo e de Física estão sendo organizadas e desenvolvidas.

O corpus de pesquisa foi construído a partir de entrevistas semiestruturadas realizadas com dois professores-monitores das disciplinas de Cálculo e de Física, ambos professores na instituição investigada e atuantes em cursos de Engenharias em uma IES do sul do Brasil. Este tipo de entrevista consiste em um instrumento que permite a flexibilização dos processos, permitindo um olhar para as nuances mais sensíveis do fenômeno e do entrevistado (FLICK, 2004). Salientamos que existem monitores-bolsistas que são estudantes da IES investigada, mas eles não fizeram parte do estudo, embora, em alguns momentos, sejam mencionados pelos entrevistados.

O método de análise utilizado seguiu a perspectiva teórica da Análise Textual Discursiva (ATD), em acordo com as propostas de Moraes e Galiazzi (2007). A ATD “corresponde a uma metodologia de análise de dados e informações de natureza qualitativa com a finalidade de produzir novas compreensões sobre os fenômenos e discursos" (MORAES; GALIAZZI, 
2007, p. 7). É composta por um movimento em três ciclos: a unitarização, a categorização e a comunicação do novo emergente.

As categorias emergentes do processo de análise em nossa pesquisa são apresentadas na seção a seguir.

\section{Resultados e discussões}

Esta seção apresenta as categorias que emergiram do processo de análise nesta pesquisa. Elas expressam as percepções dos professores-monitores responsáveis pelo trabalho em Cálculo e em Física. São elas: organização e funcionamento das monitorias; ações desenvolvidas nas monitorias; conteúdos abordados nas monitorias; e tempo dedicado às monitorias. A seguir apresentamos esses elementos, articulando as falas dos entrevistados, a teoria considerada e nossas próprias compreensões alcançadas durante o processo.

\section{V.1 Organização e funcionamento das monitorias}

Nessa categoria trazemos os aspectos organizacionais e de funcionamento das monitorias na instituição estudada. Aqui, aliamos as falas dos entrevistados com as nossas compreensões, trazendo uma abordagem geral sobre as ações. As falas dos monitores, em itálico, estão assim identificadas: professor de Cálculo (PC); professor de Física (PF).

Constatamos que as monitorias foram organizadas com base em reuniões com os coordenadores de cursos, nas quais foram amplamente discutidas as dificuldades dos estudantes. Foram traçadas, inicialmente, três ações para enfrentar as dificuldades presentes nas disciplinas: minicursos virtuais, cursos de nivelamento presenciais e monitorias.

Os minicursos virtuais ocorrem em um ambiente virtual de aprendizagem. Contemplam os conteúdos de Matemática Básica - do Ensino Fundamental e Médio - para os cursos de Engenharia e Matemática Financeira e Estatística para os cursos de Administração e Gestão. Possuem desenvolvimento de forma online, com uma certificação de 40 horas que pode ser validada como horas complementares (atividades exigidas para a conclusão da graduação).

Os cursos de nivelamento presenciais compreendem as dificuldades específicas dos estudantes de Engenharias em relação às ciências exatas. Conforme o professor-monitor de Cálculo, "as demandas foram: vetores, trigonometria, funções trigonométricas, operações numéricas, por incrível que pareça, funções do primeiro e segundo graus" (PC). Os coordenadores de cursos comunicam as necessidades aos professores designados para esse fim, e esses docentes organizavam as ações, que ocorrem aos sábados pela manhã. Os cursos/testes de nivelamento são práticas comuns no Ensino Superior das ciências exatas. Temos como exemplo disso o curso de pré-cálculo implementado pela UFRGS e um curso de nivelamento com tópicos de Matemática Básica proposto por Frescki e Pigatto (2009) em sua pesquisa. 
A monitoria, foco de nossa pesquisa, consiste em uma iniciativa para qualificar a aprendizagem de diversas disciplinas, tais como Álgebra Linear, Cálculo (Zero, I e II), Dinâmica, Equações Diferenciais, Física (I e II), Matemática Financeira e Métodos Quantitativos. "Na verdade, nós só temos [monitorias] para aquilo que ninguém entende (risos)" (PC). A fala bem-humorada do professor-monitor de Cálculo parece revelar uma certa naturalidade em relação às dificuldades nessas áreas, o que é corroborado pelas pesquisas de Oliveira e Raad (2012), que percebem as dificuldades e a reprovação, especialmente em Cálculo, como algo pertencente à própria cultura. Por meio das entrevistas percebemos que, na IES investigada, existem duas modalidades de monitorias: uma realizada por um professor da área, o qual denominamos professor-monitor, e outra realizada por estudantes, que denominamos monitor-bolsista. A escolha do bolsista se dá por meio de processo seletivo no qual se considera a indicação do coordenador do curso e a análise do desempenho acadêmico do candidato, de maneira especial na disciplina em que o aluno deverá atuar.

\section{V.2 Ações desenvolvidas nas monitorias}

A monitoria é uma atividade extracurricular realizada com o intuito de qualificar a aprendizagem e potencializar o sucesso acadêmico do estudante. Inicialmente, verificamos que, na disciplina de Cálculo, existem indícios de um trabalho colaborativo entre o professor-monitor e o bolsista, uma vez que por meio da fala de PC percebemos uma integração das práticas: "A gente acompanha, muitas aulas eles assistem comigo para entenderem o processo" (PC). $\mathrm{O}$ professor oferece um suporte, acompanhando e orientando o bolsista no desempenho da sua tarefa. Essa prática é importante para o trabalho do bolsista, conforme afirma Natario (2001) em sua pesquisa:

\footnotetext{
O monitor é considerado um agente do processo ensino-aprendizagem, capaz de intensificar a relação professor-aluno-instituição. Sendo assim, a colaboração com o professor deve ser participativa: o monitor poderá e deverá reunir-se com o docente para juntos elaborarem um plano de trabalho, considerando percepções, ideias, observações sobre os alunos e sobre a instituição, e realizando encaminhamentos concretos, que vão desde a adequação dos objetivos propostos pelo programa de ensino, até a avaliação das condições de realização da programação, a preparação de aulas, a checagem dos procedimentos, estratégias e avaliações, além de outras questões que possibilitem discutir e providenciar ações que favoreçam o ensino e a aprendizagem (p. 30).
}

Outro fato para o qual atentamos foi o suporte oferecido pelo professor-monitor ao bolsista em relação aos conteúdos. "Não quer dizer que eles são monitores, eles me chamam 'professora eu não consegui resolver essa"' (PC). Essa fala indica que o monitor não está sozinho na realização de suas tarefas, ele tem o apoio do professor para a resolução de questões de maior complexidade e que ele ainda não consegue resolver sozinho. Segundo relata PC, na continuidade de sua entrevista, este suporte não se restringe aos conteúdos conceituais de 
Cálculo, envolvendo também o planejamento das atividades a serem desenvolvidas. Dias (2007) retrata a importância da parceria professor e monitor, afirmando que o bolsista não pode ser um substituto do professor, nem pode desenvolver as atividades de forma mecânica, sem refletir sobre elas. Para a autora, o exercício da monitoria é uma oportunidade de desenvolvimento pessoal e profissional que somente ocorrerá quando o estudante estiver imerso no contexto acadêmico, com a devida mediação de um professor da disciplina.

$\mathrm{Na}$ monitoria de Física, entretanto, não foi constatado o envolvimento entre o monitor e o professor-monitor, que parece conhecer superficialmente o grupo ao informar desconhecimento inclusive sobre o número de bolsistas atuantes: "Não sei quantos tem, mas de Física deve ter um ou dois" (PF). Ele ainda relata que são realizados dois trabalhos distintos: um realizado por ele e outro pelos monitores. Para PF a diferença está no fato de que a ação desenvolvida pelos monitores tem uma abordagem mais focada nos conteúdo diretamente demandado pela disciplina, enquanto a perspectiva dele, professor, trabalha nas lacunas conceituais que o estudante apresenta: "O monitor, ele vai te explicar um passo a passo, uma solução, algum conceito e eu enquanto professor fico atento à deficiência daquele estudante, ou seja, onde ele tá com déficit, onde ele não tá e eu foco nisso" (PF). Essas falas parecem indicar atuação separada do professor e do monitor, parecendo ainda que a ação do monitor se limita a questões pontuais.

Entretanto, pensamos ser de extrema importância a realização de um trabalho colaborativo entre professor-monitor e monitor-bolsista, visto que ambos se beneficiam desta colaboração, pois, como afirma Paulo Freire em Pedagogia da Autonomia: "Quem ensina aprende ao ensinar. E quem aprende ensina ao aprender" (FREIRE, 1996, p. 25). Além disso, o estudante que acessa as duas modalidades de monitoria se beneficia desta parceria, conforme expressa Natario (2001, p. 30):

O monitor, conhecendo a situação de ser aluno nessa mesma disciplina, consegue captar não só as possíveis dificuldades do conteúdo ou da disciplina como um todo, mas também apresentar mais sensibilidade aos problemas e sentimentos que o aluno pode enfrentar em situações variadas como vésperas de avaliações, acúmulo de leituras e trabalhos, início e término de semestre etc.

Nas monitorias de Cálculo existem indicativos de um trabalhado neste sentido. PC considera que o trabalho do monitor vai além dos conteúdos: "Ele aprende a lidar com as pessoas, então é aprendizagem não só para o aluno monitor como para a gente também né? A gente se torna até um professor melhor" (PC). O entrevistado segue afirmando que a relação social estabelecida pelos monitores com colegas e professores é um dos maiores benefícios para os que estão envolvidos. Em virtude disso, vemos o trabalho colaborativo entre o professormonitor e o monitor-bolsista como benefício para todas as partes envolvidas nesse processo, pois ambas as monitorias possuem relações diferentes entre si. Por exemplo, ao realizar a monitoria com o professor-monitor, o estudante pode descobrir algum déficit conceitual da Educação Básica devido à experiência docente do professor, que está atento a essas questões. Já 
com o bolsista a relação tende a ocorrer em um contexto de amizade, de troca afetiva. De acordo com Cardoso (1997), os estudantes procuram os bolsistas, na maioria das vezes, para conferir trabalhos, pedir explicações e solicitar materiais para estudos.

$\mathrm{Na}$ instituição pesquisada, ambas as modalidades de monitorias (com professor-monitor ou com monitor-bolsista) podem ser realizadas de maneira individual ou coletiva, não havendo um padrão definido. A forma de atendimento relaciona-se ao número de estudantes que comparecem, e esse tende a sofrer variações que fogem do controle do professor-monitor. PF enfatiza: "Às vezes eu atendo vários ao mesmo tempo, então o que que eu faço? Depois que eu dei a explicação geral eu faço que eles produzam alguma coisa durante a monitoria, ou seja, faz esse exercício aqui, me chama quando você tiver dúvida" (PF). Essa prática parece ir na contramão das propostas de Cury e Cassol (2004, p.34), que sugerem "metodologias e recursos variados e, especialmente, destinados para atendimento individual, seja com monitores, seja com bolsistas de iniciação científica”. Um número excessivo de participantes em uma mesma atividade pode comprometer a qualidade do atendimento e não cumprir a proposta de preencher as lacunas conceituais dos estudantes.

Em seu relato, PF indica que o seu ponto de partida é uma explanação geral e que, na sequência, realiza uma explicação individual, focando nos pontos de dificuldades de cada estudante. Novamente, essa abordagem ocorre no sentido oposto das propostas de Cury e Cassol (2004), que defendem a identificação do erro como ponto inicial para as práticas pedagógicas. Nesse sentido, parece ser necessário um mapeamento inicial em relação às dificuldades apresentadas, pois o estudante não tem condições de identificá-las por si só. Nesse contexto, a monitoria avança partindo da identificação do erro para posterior solução, ampliando a sua dimensão.

Em síntese, percebemos que o foco de ambas as monitorias parece ser o conteúdo específico, essencialmente aquilo que o próprio estudante identifica ou questiona. Também constatamos algumas distinções entre as monitorias de Cálculo e de Física no sentido da ação da equipe, que parece trabalhar de forma mais próxima na monitoria de Cálculo. PC relata que existem reuniões com os monitores de Cálculo e são traçadas metas conjuntamente para o melhor funcionamento do trabalho. Não foi identificada condição similar em relação à Física.

Também ressaltarmos que, para um bom desempenho do monitor-bolsista em sua prática, é necessária a articulação com os docentes responsáveis pela disciplina que ele ministrará nas monitorias. Cardoso (1997) sugere que a universidade possua programas para orientar os monitores e, dentre os elementos que ele destaca como indispensáveis nesse processo, cita que o monitor-bolsista deve ter um professor-orientador, deve desenvolver atividades de ensino, pesquisa e extensão, além de receber capacitação didática para que possa preparar e ministrar aulas teóricas e práticas sob a supervisão de docentes.

Por ora, conclusas essas discussões, a seguir consideramos o ensino e a aprendizagem dentro desse contexto. 


\section{V.3 Conteúdos abordados nas monitorias}

Nesse momento centramos nossas análises nos aspectos relacionados aos conteúdos e à forma que eles aparecem nas monitorias. Podemos considerar que o conteúdo é um dos pontos cruciais da monitoria, porém não basta a sua transmissão. São necessárias ações que encaminhem para a construção do conhecimento.

A não compreensão do conteúdo específico pode gerar a retenção e a evasão dos estudantes, fenômenos comumente relacionados aos casos de insucesso durante a vida acadêmica. Vale a pena destacar que neste trabalho assumimos o entendimento de que, entre os estudantes que frequentam as monitorias, a aprendizagem de determinado conceito, ou conteúdo, não ocorreu por alguma carência ou lacuna durante o processo de ensino, ou seja, esses alunos não possuem dificuldades de aprendizagem, apenas não aprenderam o conteúdo no tempo devido, embora os entrevistados tratem o "não aprendido" como dificuldade dos estudantes.

Essas lacunas podem ser provenientes de um Ensino Fundamental e Médio que não contemplou as necessidades conceituais demandadas no Ensino Superior (CAVASOTTO; VIALI, 2011). Percebemos esse fato nas falas de PF e PC. "A gente viu que os alunos não tinham aquelas habilidades matemáticas necessárias daquele aluno que frequenta, vamos imaginar o Ensino Regular" (PC). Esse ponto foi amplamente considerado pelos entrevistados, que fizeram referência à formação do estudante e também às atividades que eles exercem no âmbito profissional, conforme as palavras de PC: "A gente tem muito assim, aluno da Educação de Jovens e Adultos (EJA), alunos que trabalham o dia inteiro, alunos com mais dificuldades" (PC). A fala parece revelar um aparente entrave em relação à formação básica dos estudantes e também em relação ao tempo dedicado aos estudos fora da sala de aula, outro aspecto muito referido.

Outras verbalizações dos entrevistados ampliam essa dimensão, indicando que o estudante também preenche eventuais lacunas conceituais ao frequentar as monitorias: "Eles precisam desse apoio para resgatar essa deficiência que basicamente é uma deficiência do histórico escolar deles" (PF). Supomos que a fala de PF seja um eufemismo para dizer que o estudante chega ao Ensino Superior despreparado e que a monitoria oferece um suporte para isso ser superado. A leitura dessa fala nos leva a considerar os argumentos de Cury e Cassol (2004) que preconizam a análise de erros como ponto de partida para a ação docente. Quem sabe a monitoria poderia se tornar mais efetiva se mapeasse as dificuldades apresentadas pelos estudantes para, a partir daí, traçar o seu desenvolvimento de forma planejada.

Em Física, a falta de base matemática também é identificada e do mesmo modo parece dificultar o avanço e o sucesso dos estudantes na disciplina. Nas palavras de PF: "Mas talvez a matemática atrapalhe mais" (PF). Além disso, também são apontadas imperfeições na interpretação textual e no entendimento e aplicação de conceitos físicos. Essa amplitude de pontos de dificuldades parece sugerir a necessidade de um trabalho interdisciplinar que vise o estudante em sua integralidade. Confirmamos essa ideia na seguinte fala: "Não entendeu uma parte específica do conteúdo de Física, geralmente não é só isso, envolve mais coisas" (PF). Guerra et al. (1998) discutem que o ensino, de uma forma geral, vem sendo constituído por disciplinas 
compartimentadas, o que promove uma ideia equivocada de que o mundo também seja fragmentado. A própria ideia de educação já não segue mais esse molde fragmentado, sendo atualmente as disciplinas englobadas em áreas do conhecimento.

Por meio das falas de ambos os professores-monitores percebemos que, em relação aos conteúdos, a maior dificuldade dos estudantes advém da não apropriação de conceitos básicos na área da Matemática (vistos na Educação Básica), e da dificuldade de interpretação dos enunciados dos exercícios. Nessa perspectiva, sugerimos que o trabalho entre a monitoria de Física e de Cálculo possa se dar de uma forma mais conjunta, de forma a identificar as necessidades conceituais de cada estudante para o avanço em relação aos conteúdos desenvolvidos durante as aulas regulares, visando efetivar melhor o tempo utilizado pelos estudantes para comparecer às monitorias.

\section{V.4 Tempo dedicado às monitorias}

Considerando a monitoria como uma ação realizada fora do horário regular de estudos e considerando um perfil de estudante trabalhador, a questão do tempo dedicado à monitoria emerge como um elemento significativo.

Os entrevistados consideraram a falta de tempo como um entrave à participação dos alunos em monitorias, em virtude da carga horária de trabalho e da própria disposição e motivação pessoal. "Mas nem todo mundo consegue comparecer, ou por interesse, ou o principal motivo, eles trabalham né?" (PF). Entretanto, ambos os professores-monitores concordam que, apesar da carga de trabalho, muitos estudantes frequentam as monitorias, como identificado na fala a seguir: "Tem dias que eu começo às três da tarde e vou até às sete da noite dando aula para os alunos toda hora. São bastantes atendimentos. E pelo que percebi, faz uns dois anos que eu estou nisso, cada vez vem aumentando mais" (PC). Nesse sentido, Cavasotto e Viali (2011) argumentam que ainda não existe um hábito consolidado de procura pela monitoria, mesmo com horários flexíveis à disposição. Consideramos ser necessário as instituições e os professores continuarem a incentivar e a fomentar o trabalho da monitoria, pois, segundo Dias (2007), por meio dela é possível que o estudante estabeleça uma relação distinta com o objeto do conhecimento que supere a ideia de memorização e cópia.

Esse hábito de frequentar regularmente a monitoria parece ainda não estar consolidado no cenário desta investigação. Segundo os entrevistados, enquanto alguns procuram a monitoria apenas na véspera das avaliações, outros a frequentam regularmente para suprir eventuais necessidades ou mesmo para construir uma base de pensamento matemático e conceitual. A fala "Nos períodos próximos à época de provas tem mais procura" (PF) ilustra a situação da procura, assim como as seguintes palavras de PC: “Claro que também tem aquele caso que só vem ali porque a prova é amanhã" (PC). Essas expressões dos entrevistados corroboram a perspectiva indicada por Cavasotto e Viali (2011), que chamam atenção para o uso, por parte dos estudantes, da monitoria como um "último recurso", não a reconhecendo como algo relevante para a sua formação. 
Identificamos a frequência contínua às monitorias como uma possibilidade de ampliação do conhecimento, como expressam os dois professores entrevistados: "Mas alguns acompanham desde o começo" (PF) e "A maioria vem antes, eles vêm procurar, eles querem saber, querem aprender" (PC). As falas evidenciam uma distinção entre as monitorias: enquanto em Física "alguns" procuram a monitoria somente antes das avaliações, em Cálculo é a "maioria" dos estudantes que agem desta forma. A distinção identificada pode ser compreendida a partir das ideias de Oliveira e Raad (2012), que apontam para a cultura de reprovação no ensino de Cálculo, o que pode levar o estudante a dedicar maior atenção a esta disciplina em função de um possível temor de insucesso.

Mesmo com distinções na forma de o estudante frequentar e perceber a monitoria, constatamos que existem possíveis resultados positivos alcançados, conforme argumenta PC: "Eles te encontram no corredor e dizem 'olha professora, me ajudou, fui bem" (PC). Esse relato parece levar em conta especialmente a questão da nota, no sentido de o estudante ter uma potencialização no seu desempenho, reduzindo os casos de insucesso. Esse benefício chega às demais partes envolvidas: "A monitoria faz bem tanto para quem frequenta quanto para o aluno-monitor (bolsista)" (PF, grifo nosso). Esse relato vai ao encontro da perspectiva indicada por Dias (2007), que considera ser possível, na monitoria, estabelecer uma construção pessoal e profissional dos envolvidos.

No decorrer desta pesquisa, tivemos a oportunidade de conhecer algumas das múltiplas facetas da monitoria. $\mathrm{O}$ envolvimento que foi desenvolvido nos levou a traçar algumas perspectivas para interlocuções posteriores, as quais indicamos na próxima seção.

\section{Considerações para futuros estudos}

Provisoriamente findadas as discussões propostas neste artigo, elencamos algumas percepções e sugestões passíveis de serem traçadas. Não temos o intuito de elaborar um corolário de resultados, mas de trazer algumas compreensões alcançadas para futuras discussões e estudos.

Inicialmente, consideramos que a Física e o Cálculo compartilham uma base comum de linguagem e de conceitos. Não causa espanto o fato de que ambos os entrevistados indiquem dificuldades comuns que abarcam conteúdos da Educação Básica e da formação inicial do estudante. No entanto, não identificamos uma proposta integrada entre as monitorias das disciplinas de Cálculo e Física. Sugerimos, então, que ambas as monitorias possam se articular de forma conjunta, pressupondo, inclusive, planejamento de forma unificada. Para que isso seja possível, parece ser necessária a existência de um espaço para debate/estudo entre os monitores, bolsistas e professores a fim de que possam traçar ações coletivas. Além disso, o uso de objetos de aprendizagens digitais contemplando as duas áreas também parece ser uma alternativa para o fortalecimento das monitorias.

Percebemos que existem dois tipos de monitoria: uma ministrada pelo professor e outra pelo bolsista. Notamos diferenças entre essas duas modalidades. $\mathrm{O}$ acesso à monitoria do 
professor tende a ser mais facilitado em função da proximidade do estudante com ele e de o professor possuir um horário fixo de atendimento, podendo o estudante comparecer a qualquer momento. Já a monitoria com o bolsista ocorre mediante um agendamento prévio com o sistema de ensino, dependendo da disponibilidade de horário, o que pode dificultar o atendimento.

Outro fator que notamos refere-se à relação professor-monitor e bolsistas. Na disciplina de Cálculo percebe-se um trabalho mais próximo entre as partes, enquanto na monitoria de Física os trabalhos parecem ocorrer de forma separada, mesmo que convirjam para o mesmo fim. Sugerimos, a partir das entrevistas e do referencial teórico considerado, uma proposta integrada em que o professor oriente os bolsistas e ambos desenvolvam um projeto colaborativo.

Também parece ser necessário um trabalho integrado entre o professor da disciplina e o sistema de monitoria. O professor pode encaminhar e acompanhar a evolução do estudante e até mesmo indicar os aspectos que ele considera relevantes para a sua disciplina. Isso pressupõe integração das partes, bem como o controle da participação e das atividades desenvolvidas. Assim, monitoria ocorrendo em sincronismo com o trabalho docente pode contribuir mais substancialmente para a formação do estudante.

Como última observação, postulamos que o assunto tratado neste artigo é relevante especialmente em relação à formação do futuro engenheiro. Por tratar-se de um olhar para apenas uma instituição, salientamos a necessidade de outras pesquisas que corroborem, ou mesmo contraponham, as percepções aqui indicadas. Desse modo, estaremos ampliando a compreensão sobre o fenômeno investigado.

\section{Referências}

AZAMBUJA, C. R. J.; SILVEIRA, F. A. R. S.; GONÇALVES, N. S. Tecnologias síncronas e assíncronas no ensino de cálculo diferencial e integral. In: CURY, H. N. (Org.). Disciplinas matemáticas em cursos superiores: reflexões, relatos, propostas. Porto Alegre: EDIPUCRS, 2004. cap. 9 , p. 225-243.

CARDOSO, S. M. V. A relação professor-aluno na construção do conhecimento: a questão da monitoria. Universidade São Francisco [texto não publicado], 1997.

CAVASOTTO, M.; VIALI, L. Dificuldades na Aprendizagem de cálculo: o que os erros podem informar. Boletim GEPEM, Rio de Janeiro, n. 59, p. 15-33, dez. 2011.

CURY, H. N., CASSOL, M. Análise de erros em Cálculo: uma pesquisa para embasar mudanças. Acta Scientiae, Canoas, v. 6, n.1, p. 27-36, jun. 2004.

DA SILVEIRA, F. L. Frenagem de um projétil em um meio fluido: "Qual seria a distância, dentro da água, percorrida por um projétil calibre $.50 \mathrm{com}$ massa de $50 \mathrm{~g}$ e velocidade de 850 m/s?" Caderno Brasileiro de Ensino de Física, Florianópolis, v. 30, n. 1, p. 156-165, abr. 2013. 
DIAS, A. M. I. A monitoria como elemento de iniciação à docência: ideias para uma reflexão. In: SANTOS, M. M., LINS, N. M. (Orgs.). A monitoria como espaço de iniciação à docência: possibilidades e trajetórias. Natal: EDUFRN, 2007. cap. 3, p. 37-44.

FLICK, U. Uma introdução à pesquisa qualitativa. Tradução: Sandra Netz. 2. ed. Porto Alegre: Bookman, 2004. 312p.

FREIRE, P. Pedagogia da autonomia: Saberes necessários à prática educativa. São Paulo: Paz e Terra, 1996, 148 p.

FRESCKI, F. B.; PIGATTO, P. Dificuldades na aprendizagem de Cálculo Diferencial e Integral na educação tecnológica: proposta de um curso de nivelamento. In: SIMPÓSIO NACIONAL DE ENSINO DE CIÊNCIA E TECNOLOGIA, 1, 2009. Anais... Imprensa Universitária UTFPR, 2009. p. $910-917$.

GERAB, F., VALÉRIO A. D. A. Relação entre o desempenho em física e o desempenho em outras disciplinas da etapa inicial de um curso de engenharia. Revista Brasileira de Ensino de Física, São Paulo, v. 36, n. 2, p. 1-9, jun. 2014.

GUERRA A. et al. A interdisciplinaridade no ensino das ciências a partir de uma perspectiva histórico-filosófica. Caderno Catarinense de Ensino de Física, Florianópolis, v. 15, n. 1, p. 32-46, abr. 1998.

MONROE, P. História da Educação. 10. ed. São Paulo: Nacional, 1974. 189 p.

MORAES, R.; GALIAZZI, M. do C. Análise Textual Discursiva. Ijuí, Unijuí, 2007.

MORAES, M.; TORRES, P. L. A monitoria on line no apoio ao aluno a distância: o modelo do LED. Colabor@- Revista Digital da CVA, Campinas, v. 2, n. 5, set. 2003. Disponível em: $<$ http://pead.ucpel.tche.br/revistas/index.php/colabora/article/viewFile/36/33>. Acesso em: 10 out. 2015.

MOREIRA, M. A. Enseñanza de la Física: aprendizaje significativo, aprendizaje mecánico y criticidad. Revista de Enseñanza de la Física, Guayaquil, v. 26, n. 1, p. 45-52, dez. 2014.

MÜLLER, T. J. Objetos de aprendizagem multimodais e o Ensino de Cálculo: uma proposta baseada em análise de erros. 2015. 203 f. Tese (Doutorado em Informática na Educação) Centro Interdisciplinar de novas tecnologias na Educação, UFRGS, Porto Alegre.

NATARIO, E. G. Programa de monitores para atuação no ensino superior: proposta de intervenção. 2001. 142 f. Tese (Doutorado em Educação) - Faculdade de Educação, Unicamp, Campinas. 
NITSCH, J. C.; BAZZO, W. A.; TOZZI, M. J. Engenheiro Professor ou Professor Engenheiro: reflexões sobre a arte do ofício. In: CONGRESSO BRASILEIRO DE ENSINO DE ENGENHARIA, 9, 2004. Anais. Brasília: UnB, 2004, p. 1-9.

OLIVEIRA, M. C. A., RAAD, M. R. A existência de uma cultura de reprovação no ensino de Cálculo. Boletim GEPEM, Rio de Janeiro, n. 61, p.125-137, jul./dez. 2012.

REZENDE, W. M. O Ensino de Cálculo: Dificuldades de natureza epistemológica. 2003. Tese (Doutorado em Educação) - Faculdade de Educação, Universidade de São Paulo, São Paulo.

RICHARDSON, R. J. Pesquisa Social: métodos e técnicas. São Paulo: Atlas. 1999. 245p.

SOARES, E. M. S.; SAUER, L. Z. Um novo olhar sobre a aprendizagem de matemática para a engenharia. In: CURY, H. N. (Org.). Disciplinas matemáticas em cursos superiores: reflexões, relatos, propostas. Porto Alegre: EDIPUCRS, 2004. cap. 10 p. 245-270.

YIN, R. K. Estudo de Caso: planejamento e métodos. Tradução: Ana Thorell. 4. ed. Porto Alegre: Bookman, 2010, 205 p. 